Article

\title{
Development and Validation of Rapid RP-HPLC and Green Second-Derivative UV Spectroscopic Methods for Simultaneous Quantification of Metformin and Remogliflozin in Formulation Using Experimental Design
}

\author{
Mahesh Attimarad 1,*(1), Rafea Elamin Elgack Elgorashe ${ }^{2}$, Rajasekaran Subramaniam ${ }^{3}$, \\ Mohammed Monirul Islam ${ }^{4}$, Katharigatta N. Venugopala ${ }^{1,5} \mathbb{D}$, Sreeharsha Nagaraja 1,6 (D) \\ and Abdulmalek Ahmed Balgoname ${ }^{1}$ \\ 1 Department of Pharmaceutical Sciences, College of Clinical Pharmacy, King Faisal University, \\ Al Ahsa 31982, Saudi Arabia; kvenugopala@kfu.edu.sa (K.N.V.); sharsha@kfu.edu.sa (S.N.); \\ a.balgoname@gmail.com (A.A.B.) \\ 2 Department of Chemistry, College of Science, King Faisal University, Al Ahsa 31982, Saudi Arabia; \\ relgorashe@kfu.edu.sa \\ 3 Department of Pharmaceutical Chemistry, Ikon Pharmacy College, Bheemanahalli, Bengaluru 562109, India; \\ rajasekaranpharm@gmail.com \\ 4 Department of Biomedical Sciences, College of Clinical Pharmacy, King Faisal University, \\ Al Ahsa 31982, Saudi Arabia; Mislam@kfu.edu.sa \\ 5 Department of Biotechnology and Food Technology, Durban University of Technology, \\ Durban 4001, South Africa \\ 6 Department of Pharmaceutics, Vidya Siri College of Pharmacy, Off Sarjapura Road, Bangalore 560035, India \\ * Correspondence: mattimarad@kfu.edu.sa or mattimarad@gmail.com
}

Received: 13 October 2020; Accepted: 27 October 2020; Published: 29 October 2020

Abstract: Recently, a new formulation containing metformin $\mathrm{HCl}(\mathrm{MFH})$ and remogliflozin etabonate (RGE) has been approved for the management of diabetes mellitus. However, only one analytical method has been reported for the simultaneous determination of both the analytes. Therefore, the current study was designed to develop simple UV derivative spectroscopic and rapid RP-HPLC methods for simultaneous determination of MFH and RGE. The chromatographic separation of MFH and RGE was performed using a monolithic C18 column with an optimized chromatographic conditions carried out by full factorial Box-Behnken design model. The spectroscopic technique was based on the determination of peak amplitude of second-order derivative UV spectra at zero crossings. Further, both the methods were validated and compared statistically using Student's-t-test and F-test, and employed for the concurrent estimation of MFH and RGE in laboratory mixed solutions and formulations. Perturbation plots and response surface models showed the effect of chromatographic parameters and the final chromatographic condition was selected from 47 solutions suggested by the desirability function. Further, UV spectroscopic and HPLC procedures showed good linearity in the range of $1-24 \mu \mathrm{g} / \mathrm{mL}$ and $2-150 \mu \mathrm{g} / \mathrm{mL}$ for RGE and 2-30 $\mu \mathrm{g} / \mathrm{mL}$ and $5-200 \mu \mathrm{g} / \mathrm{mL}$ for MFH, respectively. The average percent assay was found to be $99.51 \%$ and $99.80 \%$ for MFH and $99.60 \%$ and $100.07 \%$ for RGE by spectroscopic and HPLC methods, respectively. The proposed methods were simple, accurate, precise, and rapid. Therefore, they can be used for regular quality control of MFH and RGE formulations and dissolution studies as well.

Keywords: metformin; remogliflozin; HPLC; box-behnken design; derivative spectroscopy; optimization; formulation 


\section{Introduction}

Diabetes mellitus is a leading cause of death all over the world [1-3]. Hence, better glycemic control is essential to reduce diabetic complications such as kidney failure, retinopathy, neuropathy, cardiovascular complications, etc. [4]. Combination therapy using oral hypoglycemic agents having a diverse mechanism of action is generally suggested over monotherapy to achieve the desired therapeutic target and to reduce side effects [5]. Recently, a new formulation containing metformin $\mathrm{HCl}$ and remogliflozin etabonate has been approved for the management of diabetes mellitus. Metformin $\mathrm{HCl}$ (MFH, Figure 1A) is extensively used as an oral hypoglycemic drug, which has multiple modes of action, namely, reducing the intestine absorption of glucose by increasing the anaerobic metabolism of glucose in enterocytes, decreasing the rate of hepatic gluconeogenesis, and insulin sensitivity, thereby increasing the utilization of glucose by peripheral cells [6-8].<smiles>CN(C)C(=N)NC(=N)N</smiles>

(A)<smiles>CCOC(=O)OCC1OC(Oc2nn(C(C)C)c(C)c2Cc2ccc(OC(C)C)cc2)[C@H](O)C(O)[C@@H]1O</smiles><smiles>CC(C)c1c(C(=O)Nc2ccccc2)c(-c2ccccc2)c(-c2ccc(F)cc2)n1CC[C@H](O)C[C@H](O)CC(=O)O</smiles>

(C)

Figure 1. Chemical structure of metformin $\mathrm{HCl}(\mathbf{A})$, remogliflozin etabonate (B), and atorvastatin (C).

Remogliflozin etabonate (RGE, Figure 1B) is a recently developed insulin-independent oral hypoglycemic agent. [9,10]. It acts by inhibiting sodium-glucose cotransporter-2 (SGLT2), an enzyme accountable for reabsorption of sugar in the kidneys, thereby; increase the elimination of sugar in the urine. Apart from glycemic control, SGLT-2 inhibitors possess many beneficial effects that include lowering of body weight, reduction of systolic blood pressure, and lowering hemoglobin A1c levels. Hence, RGE is more helpful when co-administered with metformin, particularly in patients with cardiac and renal diseases, who require further reduction of hemoglobin A1c level [11-16].

Literature depicts many analytical methods for quantification of metformin alone using spectrophotometric [17], HPLC [18], LCMS [19], capillary electrophoresis [20] in both formulations and biological samples. Metformin was also quantified in combination with other antidiabetic drugs using spectrophotometric [21], HPLC [22-26], LCMS [27,28], capillary electrophoresis [29,30]. Metformin was also determined by the HPLC method along with canagliflozin [31] and with empagliflozin [32]. Quantification of RGE from bulk and in house tablets has been reported by Ankita et al. [33] using a spectroscopic method and high-performance thin-layer chromatography, whereas Sigafoos et al [34] utilized LC/MS method for quantification of RGE from plasma. Recently, analytical method using 
UPLC has been reported [35] for the concurrent determination of MFH and RGE from formulation. However, this study was aimed to develop simple, eco-friendly spectroscopic method and rapid RP-HPLC technique using atorvastatin as internal standard for concurrent quantification of MFH and RGE from solutions prepared in the laboratory and formulation.

The use of a direct UV spectroscopic method for the determination of multicomponent formulations is difficult if the spectra are overlapping. Hence, derivative spectroscopic methods are extensively used to resolve overlapping spectra for the concurrent determination of a combination of compounds [36-38]. In addition, the derivative techniques improve sensitivity and avoid interference from formulation excipients [36-40]. Hence, the second-derivative spectroscopic method has been performed to determine MFH and RGE simultaneously without extraction or separation of components from the formulation. As per guidelines of USFDA, the pharmaceutical industries are using quality by design methodology for developing rapid and economical RP-HPLC method [41]. The design of the experiment with multivariate optimization is generally used to optimize the analytical methods because it utilizes statistical concepts in comparing the simultaneous effects of different variables [41-47]. Further, a validated analytical method will be more efficient, rapid, and economical, as fewer experiments need to be carried out when compared with univariate optimization. Hence, the rapid RP-HPLC method has been developed using a monolithic column adopting multivariate optimization of HPLC parameters.

\section{Materials and Methods}

\subsection{Instruments}

The spectroscopic method was developed using the UV-VIS spectrophotometer (Shimadzu UV-1700, Shinagawa city, Tokyo, Japan). The instrument was attached to a personal computer installed with UV-probe software (Shimadzu Ver. 2.0, Shinagawa city, Tokyo, Japan). Analyte solutions were scanned using $10 \mathrm{~mm}$ quartz cuvettes with scan speed adjusted to fast mode, sampling intermission of $0.1 \mathrm{~nm}$, and slit width $2 \mathrm{~nm}$. An Agilent technologies HPLC instrument (Agilent 1200 series, Waldbronn, Germany) used was connected to mobile phase degasser, quaternary pump, autosampler, and diode array detector. Chem station (Ver. B 4.0.2) Agilent software was used to monitor the signals.

\subsection{Analytes and Reagents}

Active pharmaceutical ingredients of metformin $\mathrm{HCl}$ and remogliflozin etabonate were purchased from Bioteck Private Limited, Hyderabad, India. The internal standard atorvastatin calcium (AVC) was procured from Sigma Aldrich (Buchs, Switzerland). Chromosolv acetonitrile purchased from Honeywell (Morris Plains, NJ, USA) was HPLC grade and ethanol used for dissolving RGE was of analytical grade purchased from Sigma Aldrich (St. Louis, MO, USA). Sodium dodecyl sulfate (SDS), potassium dihydrogen phosphate, and orthophosphoric acid were obtained from Sigma (St. Louis, MO, USA) were analytical grade. Ultrapure water arranged in our laboratory utilizing Milli $\mathrm{Q}$ (Millipore, Burlington, MA, USA) water purification system was utilized during the investigations.

\subsection{Preparation of Standard Solutions}

All three standards MFH, RGE, and AVC were weighed accurately and dissolved separately into water, ethanol, and methanol respectively to get $1000 \mu \mathrm{g} / \mathrm{mL}$ concentration. Further, working standard and laboratory mixed solutions of MFH and RGE for UV spectroscopic methods were prepared by diluting with ultra-pure water. For the HPLC method, a series of working standard and laboratory mixed solutions of analytes along with internal standards were prepared by mixing all three solutions in the required quantity using the mobile phase. 


\subsection{Preparation of Sample Solutions}

A recently approved new combination of MFH and RGE was not available in the Saudi market, therefore, simulated tablets consisting of RGE $100 \mathrm{mg}$ along with MFH $500 \mathrm{mg} / 1000 \mathrm{mg}$ were prepared by mixing the required quantity of RGE, MFH, and tablet excipients mannitol, talc, magnesium stearate, microcrystalline cellulose, colloidal silicon dioxide, and polyvinyl pyrrolidone. Tablet powder equivalent to $100 \mathrm{mg}$ of RGE along with MFH $500 \mathrm{mg}$ and $1000 \mathrm{mg}$ were measured separately and transferred to a $50 \mathrm{~mL}$ graduated flask containing $25 \mathrm{~mL}$ ethanol. The flasks were mixed properly by sonication to dissolve the drugs. Then the solutions were filtered into other graduated flasks and the finishing volume was attained with ethanol. Further, to achieve the amount of the drugs in the linearity range the sample solutions were diluted with water and the mobile phase for the UV spectroscopic and chromatographic methods, respectively.

\subsection{Chromatographic Conditions}

The chromatographic separation of MFH, RGE, and IS was achieved on a Chromolith (50 $\mathrm{mm} \times 4.6 \mathrm{~mm}$ i.d. $5 \mu \mathrm{m}$ particle size) (Merck, Darmstadt, Germany) C18 column with isocratic elution. The mobile phase utilized for the separation of analytes and IS was comprising of acetonitrile and mixture of $25 \mathrm{mM}$ sodium dodecyl sulfate, $10 \mathrm{mM}$ potassium dihydrogen phosphate ( $\mathrm{pH}$ adjusted to 3.5 with orthophosphoric acid) in a ratio of $42 \%: 58 \%(v / v)$, respectively. The mobile phase was pumped at a rate of $2 \mathrm{~mL} / \mathrm{min}$ at room temperature. The chromatogram was recorded by measuring the UV absorbance of the eluted analytes by a diode array detector at $230 \mathrm{~nm}$. Different concentrations of working standard solutions, laboratory mixed solutions, and sample solutions were transferred into vials and placed into the auto-sampler. The injection volume of auto-sampler was set at 20 microliters for investigation.

\subsection{Optimization of Chromatographic Conditions by Experimental Design}

One of the multivariate optimization techniques, Box-Behnken design model was adopted to elevate the effect of chromatographic conditions [48-50]. The Second-order three-level full factorial design experiment was performed by 17 runs including 5 central points at low, intermediate, and high levels of variables coded as $-1,0$, and +1 respectively. The three independent variables, at three levels considered for optimization, were the concentration of sodium dodecyl sulfate $(15 \mathrm{mM}, 20 \mathrm{mM}$, and $25 \mathrm{mM})$, percent of acetonitrile $(35 \%, 40 \%$, and $45 \%)$ and $\mathrm{pH}$ of the mobile phase $(2.5,3.5$ and 4.5$)$. The 17 runs suggested by the software were run randomly to avoid any residual effects and the resolution between MFH peak to RGE peak and resolution between RGE peak to IS peak were considered as dependent response factors. Polynomial equations were generated by Design Expert software (Version 12, Stat-Ease Inc. Minneapolis, MN, USA) and its validation was performed by analysis of variance (ANOVA). A second-order quadratic model polynomial equation with coefficients of the influence of chromatographic variable parameters on the response was expressed as below:

$$
R=\delta 0+\delta 1 A+\delta 2 B+\delta 3 C+\delta 4 A C+\delta 5 A B+\delta 6 B C+\delta 7 A 2+\delta 8 B 2+\delta 9 C 2
$$

where $\mathrm{R}$ represents the response (resolution between peaks); A, B, and C are three independent variables $\%$ of SDS, $\%$ of acetonitrile, and $\mathrm{pH}$ of the mobile phase respectively; $\delta 0$ represents the intercept $\delta 1-\delta 9$ represents the regressions coefficients computed from the responses of 17 runs, showing the effects of each factors individual, square, and combined effects of factors. Both perturbation and 3D surface response models were generated using Design Expert software (Version 12, Stat-Ease Inc. Minneapolis, MN, USA) for easy representation for presenting the effect of chromatographic variable parameters on the selected response and optimize the chromatographic method. 


\subsection{Method Validation}

The developed analytical methods have to be validated as per the ICH recommendations to prove the methods proposed are suitable for quality control. Validation of the proposed techniques [51] was performed for linearity, the limit of detection, the limit of quantification, accuracy, and precision. Additionally, the HPLC technique has been validated for system suitability and robustness.

\subsubsection{System Suitability for HPLC Method}

For the HPLC method, the system suitability test was carried out by analyzing $20 \mu \mathrm{g} / \mathrm{mL}$ and $100 \mu \mathrm{g} / \mathrm{mL}$ solutions of RGE and MFH respectively by maintaining IS concentration at $50 \mu \mathrm{g} / \mathrm{mL}$. The investigation was carried out in triplicate and the various parameters determined were peak area ratios, theoretical plate, tailing factor, resolution, and retention time.

\subsubsection{Linearity}

\section{Second-derivative Spectroscopic Method}

Aliquots of MFH and RGE were transferred separately into two series of $10 \mathrm{~mL}$ graduated flask to obtain seven solutions of $2.0-30 \mu \mathrm{g} / \mathrm{mL}(2.0,5,10,15,20,25$, and $30 \mu \mathrm{g} / \mathrm{mL})$ and 1 to $24 \mu \mathrm{g} / \mathrm{mL}(1,4,8,12,16,20$, and $24 \mu \mathrm{g} / \mathrm{mL})$, respectively. The UV absorption spectra were recorded in the wavelength 200-300 $\mathrm{nm}$ using ethanol-water as blank and stored spectra were converted into second-order derivative spectra by $8 \mathrm{~nm}$ as $\Delta \lambda$ with amplification feature 100. The absorption of MFH spectra was measured at wavelength $235.5 \mathrm{~nm}$, a zero crossing for RGE. Similarly, the peak amplitude of RGE spectra was measured at wavelength $243.0 \mathrm{~nm}$, a zero crossing for MFH. The calibration curves and regression equations were constructed from these peak amplitudes and corresponding concentrations of MFH and RGE.

\section{HPLC Method}

The required quantity of MEF and RGE was transferred to series of vials to get the eight concentrations levels in between 5 to $200 \mu \mathrm{g} / \mathrm{mL}(5,50,75,100,125,150$ and $200 \mu \mathrm{g} / \mathrm{mL})$ and 2 to $150 \mu \mathrm{g} / \mathrm{mL}(2,25,50,75,100,125$ and $150 \mu \mathrm{g} / \mathrm{mL})$ respectively. Further, an aliquot of the IS solution was transferred to all the vails to get a concentration of $50 \mu \mathrm{g} / \mathrm{mL}$. Chromatographs were documented by injecting $20 \mu \mathrm{L}$ of each sample in triplicate. Peak area ratios of MEF to IS and RGE to IS, calculated from the chromatogram that were used to generate calibration curves using the corresponding concentration of MEF and RGE.

\subsubsection{Limit of Detection and Quantification}

Limit of detection and quantification explains the sensitivity of the analytical techniques. Hence, LOD and LOQ were determined for both the methods using $3.3 \mathrm{~d} / \mathrm{s}$ and $10 \mathrm{~d} / \mathrm{s}$ equations, respectively, where " $\mathrm{d}$ " is the standard deviation of the response intercept and " $\mathrm{s}$ " is the slope of the standardization curve.

\subsubsection{Precision and Accuracy}

The precision of both analytical methods was evaluated in terms of inter-day and intraday precision. For determination of inter-day precision, four diverse concentrations of MEF and RGE solutions were evaluated in triplicate on the same day covering the entire calibration range. Similarly, for the determination of intraday precision the above-prepared solutions were analyzed on three consecutive days. The precision of the method was presented as relative standard deviation (RSD). Accuracy of both the methods was evaluated using the above solutions and expressed as percent relative error (\%RE). 


\subsubsection{Recovery Studies}

The recovery of both analytes from the formulation by both analytical methods was evaluated by the standard addition method. In this, formerly evaluated sample solution consisting of a known amount of MFH and RGE were spiked with three different concentration levels 50\%, 100\%, and 150\%. Briefly, for spectroscopic method recovery study was executed by adding standard solutions of MFH $(5,10$, and $15 \mu \mathrm{g} / \mathrm{mL})$ and $\operatorname{RGE}(1,2$, and $3 \mu \mathrm{g} / \mathrm{mL})$ to the formerly studied solution containing $10 \mu \mathrm{g} / \mathrm{mL}$ of MFH and $2 \mu \mathrm{g} / \mathrm{mL}$ of RGE. Similarly, recovery study of HPLC method was performed by analyzing the solution after adding three different concentration of standard MFH $(25,50$, and $75 \mu \mathrm{g} / \mathrm{mL})$ and RGE $(5,10$, and $15 \mu \mathrm{g} / \mathrm{mL})$ to the formerly examined sample comprising of $50 \mu \mathrm{g} / \mathrm{mL} \mathrm{MFH}$ and $10 \mu \mathrm{g} / \mathrm{mL}$ RGE. Further, $50 \mu \mathrm{g} / \mathrm{mL}$ of IS was maintained in these solutions. The recovery study result was expressed in terms of percent recovery and percent relative error.

\subsubsection{Robustness Using Experimental Design}

The robustness of the liquid chromatographic procedure for the concurrent determination of MFH and RGE was evaluated by fractional factorial design. The parameters were slightly but deliberately changed from the optimized conditions for both analytes to study their effect on the considered response. The three parameters designated on the importance of parameters witnessed during experimental runs were a percentage of acetonitrile $(40 \%, 42 \%$, and $44 \%), \mathrm{pH}(3.3,3.5$, and 3.7$)$ of the mobile phase and flow rate $(1.8 \mathrm{~mL} / \mathrm{min}, 2 \mathrm{~mL} / \mathrm{min}$ and $2.2 \mathrm{~mL} / \mathrm{min})$. The responses examined were peak area ratios of MFH to IS and RGE to IS. The responses recorded were explored with design expert software to know the effect of simultaneous changes in the parameters. The experiments were accomplished in random order to avoid the influence of unrestricted features. The Pareto chart was generated from the peak area ratios obtained for both analytes, to know the effect of slight changes in the experimental conditions.

\subsection{Analysis of Laboratory Mixed Solutions and Formulations}

For spectrophotometric method, six solutions consisting of both analytes in different ratios of 2:5, 10:5, 10:20. 20:20, 5:30, and 20:30 $\mu \mathrm{g} / \mathrm{mL}$ of RGE and MFH were mixed. Then the UV absorption was recorded in between the wavelength 200 to $300 \mathrm{~nm}$ and the recorded spectra were converted to second-order derivative spectra. Then the peak amplitude was recorded at a wavelength of $243 \mathrm{~nm}$ for RGE and $235.5 \mathrm{~nm}$ for MFH. The concentrations were computed from the respective regression equations. Similarly, formulation samples were analyzed by diluting the formulation solutions to get an amount of analytes in the range of calibration curve. The formulation is available in two different ratios of RGE and MFH; hence, samples for each strength were prepared and analyzed.

For HPLC analysis various aliquots of standard solutions of RGE and MFH were transferred to vials to get the concentration in different ratios of 5:25, 5:100, 75:200, 75:100, 150:25, 150:200 $\mu \mathrm{g} / \mathrm{mL}$, respectively by maintaining the IS concentration at $50 \mu \mathrm{g} / \mathrm{mL}$. The experiments were conducted as per the optimized procedure explained in the chromatographic condition and the quantity of both analytes, was computed using the respective regression equations. Further, the optimized HPLC method was utilized for the determination of RGE and MFH from the dosage form without prior separation. Assay of in house prepared tablets consisting of $100 \mathrm{mg}$ of RGE and $500 \mathrm{mg} / 1000 \mathrm{mg}$ of MFH was performed for each tablet. The percent drug content was determined by employing the respective linearity equations.

\section{Results and Discussion}

The second-order derivative UV spectrophotometric technique was developed for the simultaneous quantification of RGE and MFH because zero-order UV spectra of RGE and MFH showed complete overlap (Figure 2A). Further, derivatization eliminates the absorption effects of co analytes and excipients. Different order derivative spectra were studied, the first derivative spectra of MFH and RGE showed only one zero crossings and second-order derivatization showed better precision with $\Delta \lambda$ 
$8 \mathrm{~nm}$ with a scaling factor of 100 , hence, the 2 nd derivative has been selected for analysis of the binary mixture. Further, the second-order derivatization of RGE displayed two zero crossings at wavelength $220.1 \mathrm{~nm}$ and $235.5 \mathrm{~nm}$ where MFH had some absorption, whereas MFH showed two zero crossings at wavelength $225.9 \mathrm{~nm}$ and $243.0 \mathrm{~nm}$ where RGE had good peak amplitude. However, RGE showed better amplitude at $225.9 \mathrm{~nm}$ but the sensitivity was good at $243.0 \mathrm{~nm}$, hence, $243.0 \mathrm{~nm}$ was selected for further analysis of RGE. MFH showed better amplitude and good sensitivity at $235.5 \mathrm{~nm}$ compared to a wavelength of $220.1 \mathrm{~nm}$, hence, 235.5 was selected for further analysis. Furthermore, Figure 2B showed the same peak amplitude for pure standard solution spectra of RGE and MFH as of mixture of RGE and MFH spectra containing the same amount of analytes.
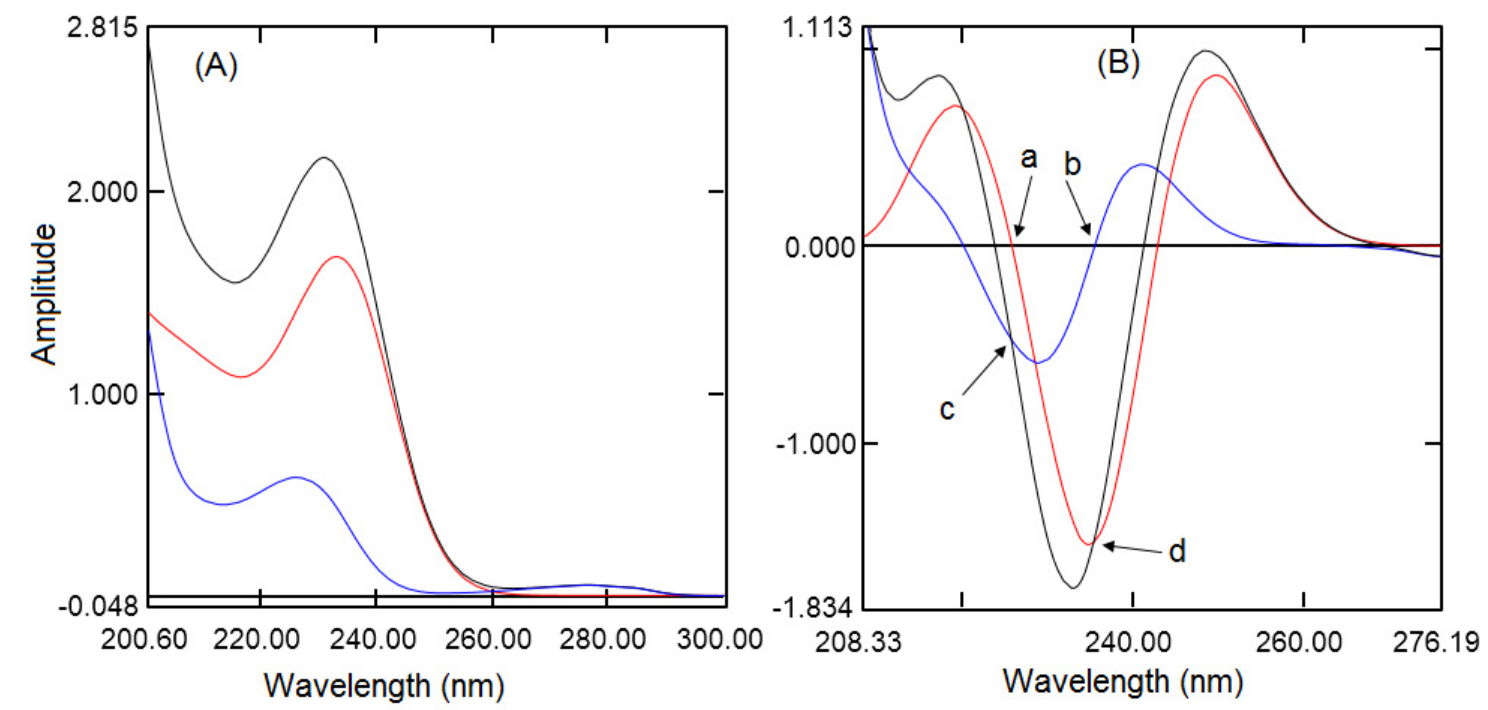

Figure 2. Normal UV absorption spectra of RGE (blue), MFH (red), and mixture (black) (A); second-derivative spectra of RGE (blue), MFH (red), and mixture (black) (B). Points a and b are zero crossings of MFH and RGE, respectively. Points $c$ and d show the same peak amplitude for RGE and $\mathrm{MFH}$ in the pure sample and mixture, respectively.

\subsection{Optimization of HPLC Method}

To develop a rapid chromatographic method monolithic column $(50 \mathrm{~mm})$ has been selected. Monolithic column, also known as silica rod, because the column is packed with one piece of porous substance with flow pores and mesopores. Large flow pores allow for use of the mobile phase at a high flow rate and small mesopores increase the total surface area for interaction with the analyte for better separation. Monolithic columns can be operated up to $10 \mathrm{~mL} / \mathrm{min}$ due to low back pressure; however, for separation of three analytes, $2 \mathrm{~mL} / \mathrm{min}$ will be appropriate. The preliminary chromatographic study demonstrated that metformin was eluted at dead volume with more than $30 \%$ organic solvents along with phosphate buffer, whereas with less than $30 \%$ of organic solvent RGE was eluted after 6 min. Hence, from our previous report [52] to increase the retention time of MFH sodium dodecyl sulfate was employed in the mobile phase and $10 \mathrm{mM}$ potassium dihydrogen phosphate was sufficient to give sharp peaks. Further, to optimize the chromatographic condition Box-Behnken's experimental design was adopted. From the preliminary studies, the important factors considered for optimization were the amount of sodium dodecyl sulfate (A), the percentage of organic modifier (B), and mobile phase $\mathrm{pH}(\mathrm{C})$. Two responses considered were resolution between $\mathrm{MFH}$ and $\mathrm{RGE}$ and resolution between RGE and IS. To develop the Box-Behnken experimental model [47-49], the number of experiments required can be determined by the equation $\mathrm{N}=2 \kappa(\kappa-1)+\theta$, where $\kappa$ is independent parameters and $\theta$ is the number of center point experiments. Hence, two response surface models have been created form the 17 runs and applied for computing the relations between the independent variables and 
responses (Table 1). The best-fit models were suggested by the software based on the results, such as $p$-value, determination coefficients, adjusted and predicted R2 value, and model F value.

Table 1. Box-Behnken model for optimization of chromatographic condition.

\begin{tabular}{cccccc}
\hline $\begin{array}{c}\text { Experiment } \\
\text { Number }\end{array}$ & $\begin{array}{c}\text { Percent } \\
\text { SDS }\end{array}$ & $\begin{array}{c}\text { Percent } \\
\text { Acetonitrile }\end{array}$ & pH & $\begin{array}{c}\text { Resolution of } \\
\text { MFH to RGE }\end{array}$ & $\begin{array}{c}\text { Resolution } \\
\text { of RGE to IS }\end{array}$ \\
\hline 1 & 20 & 40 & 3.5 & 14.93 & 5.93 \\
2 & 25 & 40 & 2.5 & 6.11 & 5.57 \\
3 & 25 & 40 & 4.5 & 15.94 & 3.00 \\
4 & 20 & 35 & 4.5 & 26.72 & 1.54 \\
5 & 20 & 35 & 2.5 & 11.68 & 6.85 \\
6 & 25 & 45 & 3.5 & 8.36 & 4.02 \\
7 & 20 & 40 & 3.5 & 15.48 & 6.12 \\
8 & 20 & 45 & 4.5 & 10.84 & 1.38 \\
9 & 20 & 40 & 3.5 & 14.91 & 5.85 \\
10 & 15 & 40 & 2.5 & 11.15 & 6.2 \\
11 & 20 & 40 & 3.5 & 15.11 & 6.04 \\
12 & 25 & 35 & 3.5 & 18.25 & 5.11 \\
13 & 20 & 45 & 2.5 & 7.75 & 4.74 \\
14 & 15 & 35 & 3.5 & 21.59 & 5.39 \\
15 & 20 & 40 & 3.5 & 15.29 & 6.17 \\
16 & 15 & 40 & 4.5 & 19.32 & 0.87 \\
17 & 20 & 40 & 3.5 & 14.93 & 5.93 \\
\hline
\end{tabular}

The second-order polynomial equation representing the quadratic relationship was suggested by the software for resolution between MFH and RGE. This was computed using the least square method and found to be:

$$
\begin{gathered}
\text { Resolution of MFH to RGE }=-28.08831+0.3262 \% \text { SDS }-0.3811 \% A C N+ \\
36.1765 p H+0.002 \% \text { SDS }^{*} \% \mathrm{ACN}+0.083 \% \mathrm{SDS}^{*} \mathrm{pH}-0.5975 \% \mathrm{ACN} * \mathrm{pH}-0.02673 \% \\
\text { SDS }^{2}+0.01797 \% \mathrm{ACN}^{2}-1.34575 \mathrm{pH}^{2}
\end{gathered}
$$

The first order influence of percent of acetonitrile and mobile phase $\mathrm{pH}$, separately, and their simultaneous effect was found to be most significant $(p<0.0001)$ on the resolution of MFH to RGE. Further, the interaction of percent of SDS and $\mathrm{pH}$ of the mobile phase with percent of acetonitrile was also most significant. The pure quadratic effect of acetonitrile and $\mathrm{pH}$ were highly significant. However, percent of acetonitrile had a negative effect whereas mobile phase $\mathrm{pH}$ ensured a positive influence on the resolution of MFH to RGE. The predicted $R^{2}$ value $(0.9817)$ was very close to the adjusted $R^{2}$ value (0.9963) indicating satisfactory fitting of the model (since the difference is less than 0.2 ). The suggested model gave an F-value of 475.83 denotes the significant model, further the $p$-value was less than 0.05 for all parameters indicating model expressions were significant. Therefore, a quadratic model was exhibited to be significant for the resolution of MFH to RGE. Adequate precision indicates the signal to noise ratio and it was found to be 83.348 and that indicate adequate signal (A precision value more than four is desirable).

The quadratic relationship model suggested for resolution between RGE and IS by the software was found to be:

$$
\begin{gathered}
\text { Resolution of RGE to IS }=-38.44587+0.432850 \% \text { SDS }+2.04195 \mathrm{ACN} \%+ \\
2.75575 \mathrm{pH}-0.0037 \% \mathrm{SDS}^{*} \mathrm{ACN} \%+0.138 \% \mathrm{SDS}^{*} \mathrm{pH}+0.0975 \mathrm{ACN} \%{ }^{*} \mathrm{pH}-0.01884 \% \\
\text { SDS }^{2}-0.03014 \mathrm{ACN} \%{ }^{2}-1.641 \mathrm{pH}^{2}
\end{gathered}
$$

The first order influence and pure quadratic influence of percent of acetonitrile and mobile phase $\mathrm{pH}$ were most significant $(p<0.001)$, similarly, the interaction of percent of SDS and percent of acetonitrile with $\mathrm{pH}$ of the mobile phase was significant $(p<0.001)$. Further percent of acetonitrile and 
mobile phase $\mathrm{pH}$ had a positive influence on the resolution of RGE to IS. The quadratic relationship model showed a better fit of the model with reverence to its $p$-value. A narrow difference was observed between the predicted $R^{2}$ values (0.859) and the adjusted $R^{2}$ value (0.963) indicating acceptable fitting of the model (since the difference is less than 0.2 ). The model F-value of 47.25 suggests the significant model because the $p$-value was 0.0001 , which is $\leq 0.05$, showing that the model terms were significant. Hence, the quadratic relationship model was found to be significant for the resolution of RGE to IS. Adequate precision indicates the signal to noise ratio and it was found to be 20.3347, indicating a sufficient signal (a precision value more than four is desirable).

Design Expert software also provides different types of diagnostic plots, a comparison of predicted residual plots against actual plots, which help in identifying the thorough fit of the model. A good-correlated, predicted and the actual value is demonstrated by the proper scattering of both values along the average line. The model is considered statistically acceptable if the predicted R2 and adjusted $R^{2}$ values are within $20 \%$. The present model suggested by the software showed that the predicted and actual values (Figures $3 \mathrm{~A}$ and $4 \mathrm{~A}$ ) were close to each other. Similarly, normal probability residuals (Figures $3 \mathrm{~B}$ and $4 \mathrm{~B}$ ) showed that almost all residual points are adjacent to the diagonal line. Further residual plots (Figure 3C,D and Figure 4C,D) against the run number and predicted values showed a random nonlinear scattering style without any outliers. In addition, the residual points were close to the projected regression line at zero indicated the perfectness of the prediction. The residual points above the zero lines (positive values) indicates a low prediction, whereas below the zero lines (negative values) indicate over prediction.
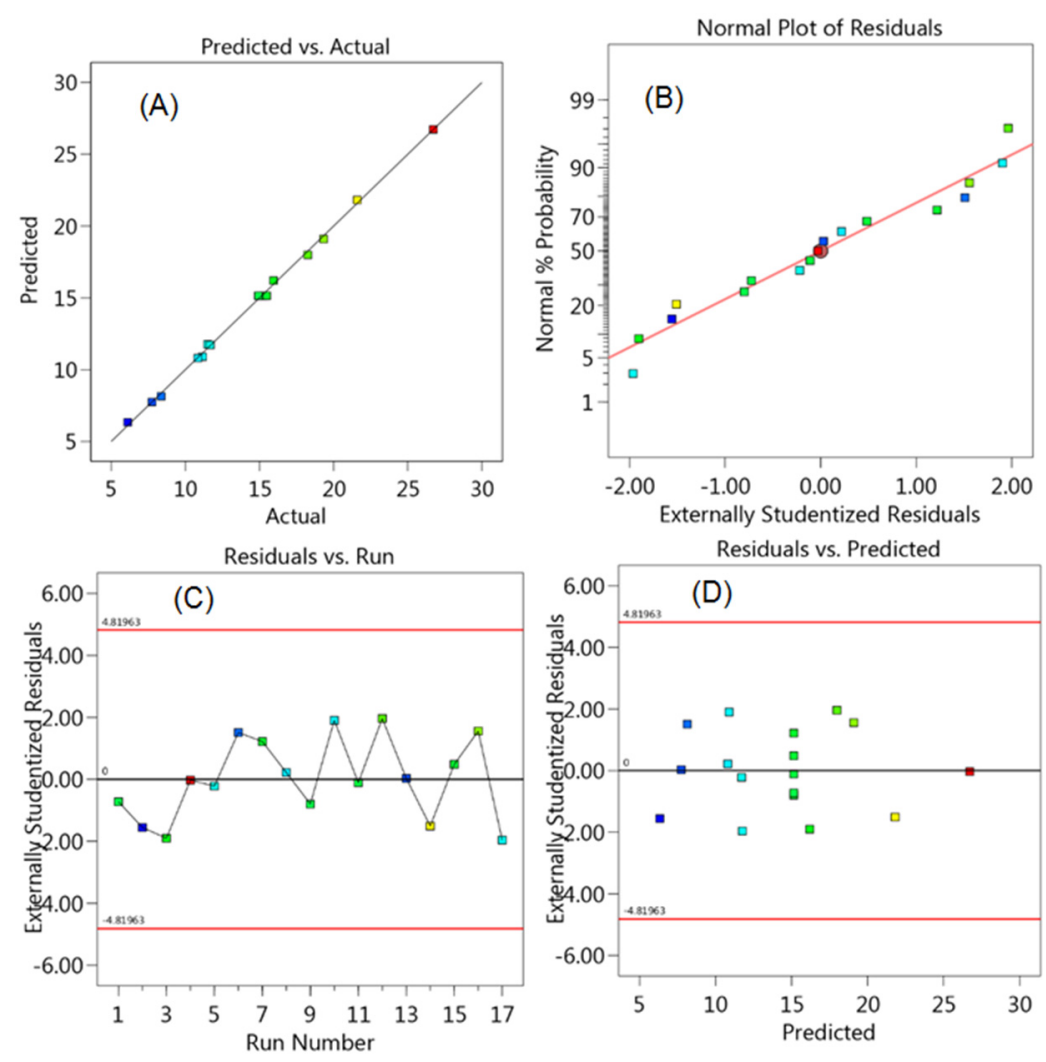

Figure 3. Diagnostic plots for resolution of MFH to RGE showing the predicted vs. actual (A) normal plot of residuals (B), residuals against run (C) and predicted values (D). 

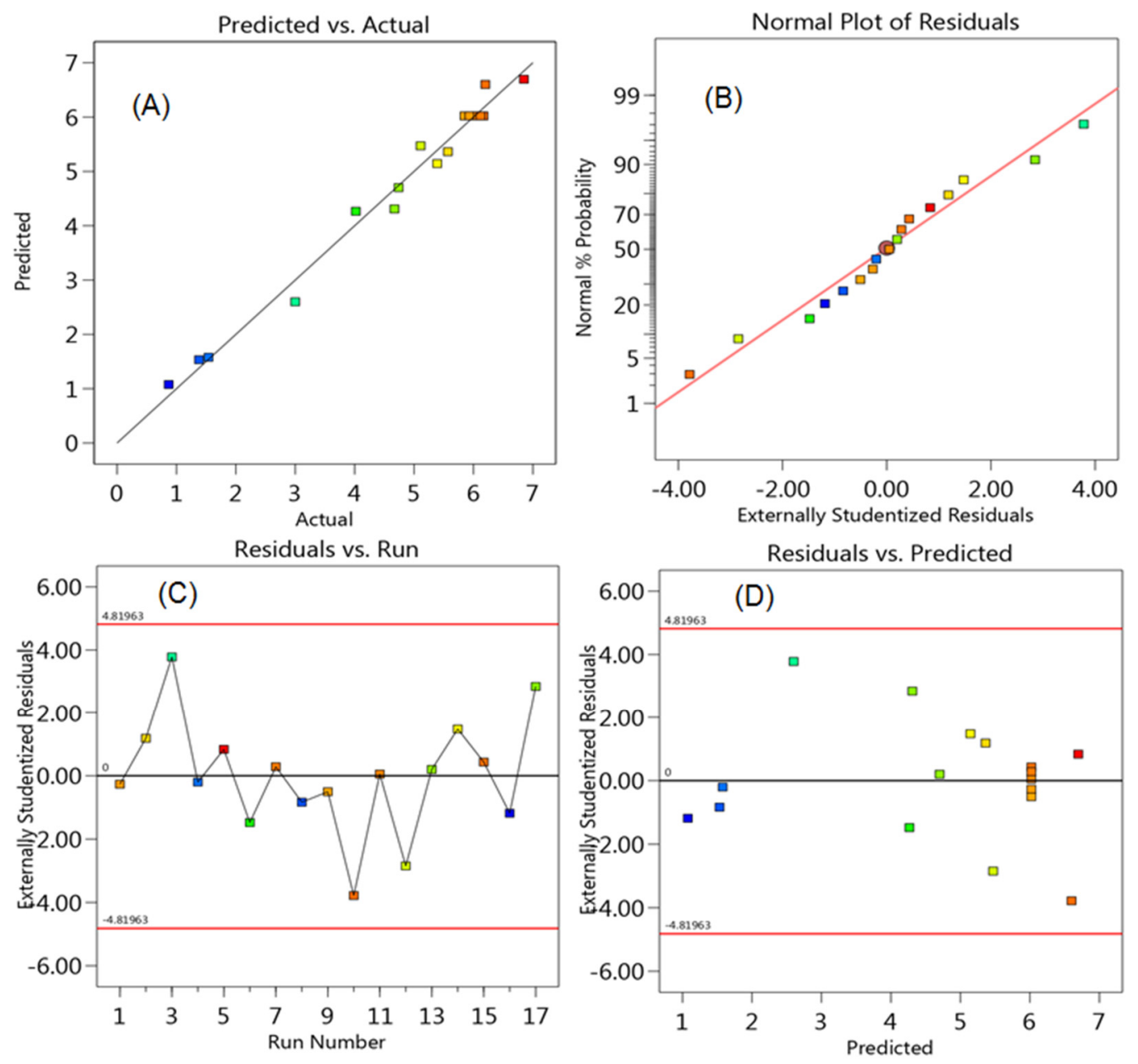

Figure 4. Diagnostic plots for resolution of RGE to IS showing the predicted vs. actual (A) normal plot of residuals (B), residuals against run (C) and predicted values (D).

The perturbation plots (Figure 5) and response surface models (RSM) clearly showed the effect of the concentration of SDS, percent of acetonitrile, and mobile phase $\mathrm{pH}$ on the resolution of drugs. The perturbation plot, Figure 5I, showed that percent of acetonitrile and mobile phase $\mathrm{pH}$ had an incredible influence on the resolution between MFH and RGE. With the decrease in the mobile phase $\mathrm{pH}$, the resolution was decreased, whereas the percentage of acetonitrile showed the opposite effect. Further percent of SDS showed a slight effect on the resolution of MFH to RGE. Figure 5II showed that with an increase in the percent of acetonitrile and mobile phase $\mathrm{pH}$, decrease in the resolution between RGE and IS. The influence of the combined effect of different factors was observed in response surface models (Figure 6). The RSM of the resolution of MFH to RGE, Figure 6A-C, showed that the decrease in the amount of acetonitrile and SDS increased the resolution, whereas an increase in the mobile phase $\mathrm{pH}$ with the decrease in the amount of acetonitrile drastically increased the resolution. Further, the increase in the $\mathrm{pH}$ of mobile phase increased the resolution without much effect of the percent of SDS. The RSM of resolution between RGE and IS (Figure 6D-F) showed that a decrease in the amount of acetonitrile and SDS showed a slight increase in the resolution. Whereas, the decrease in the $\mathrm{pH}$ along with the amount of acetonitrile increased the resolution. Similarly, the decrease in the mobile phase $\mathrm{pH}$ and amount of SDS increased the resolution. 

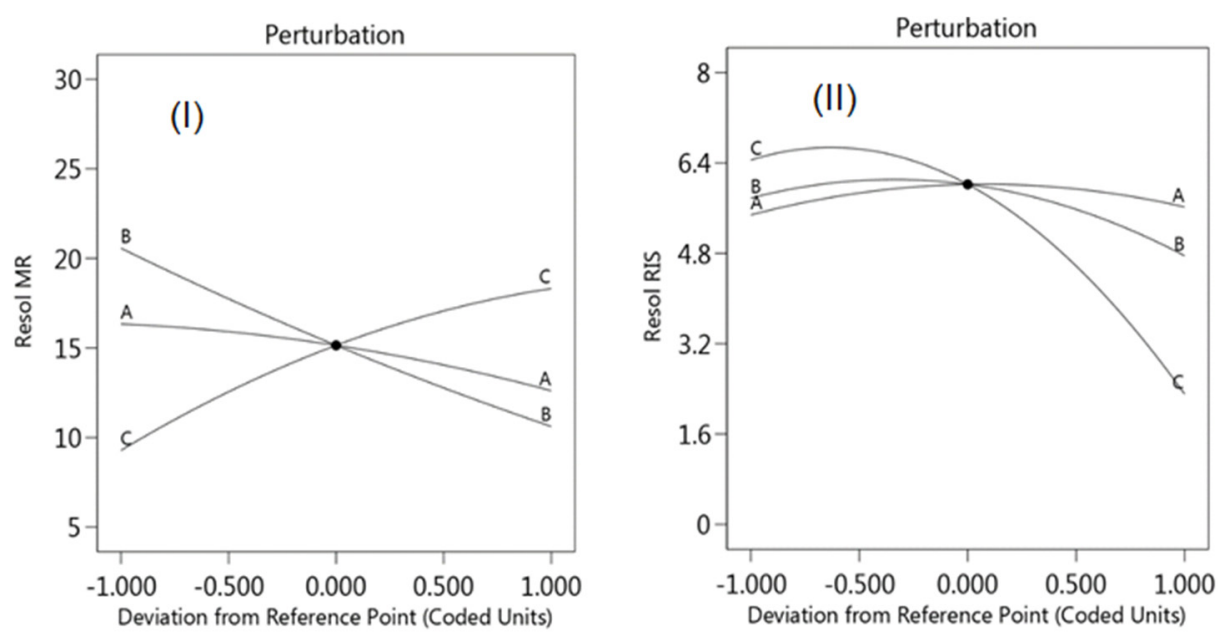

Figure 5. Perturbation plots showing the effect of percent of SDS (A), percent of acetonitrile (B) and $\mathrm{pH}$ of the mobile phase (C) on the resolution of MFH to RGE (I) and RGE to IS (II).

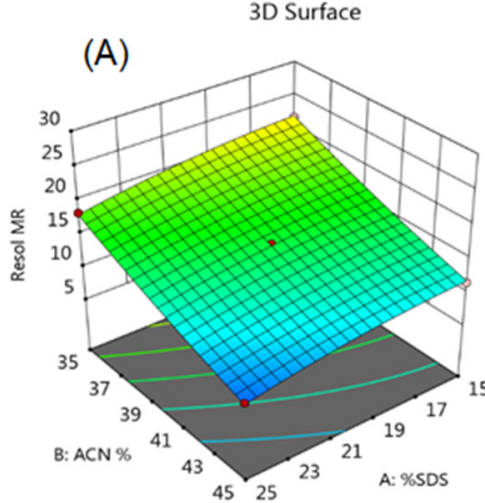

(D)

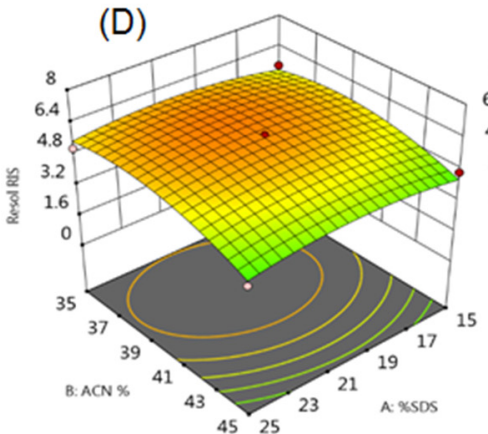

(B)

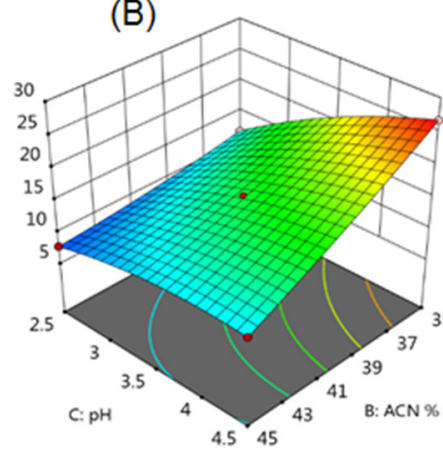

(E)

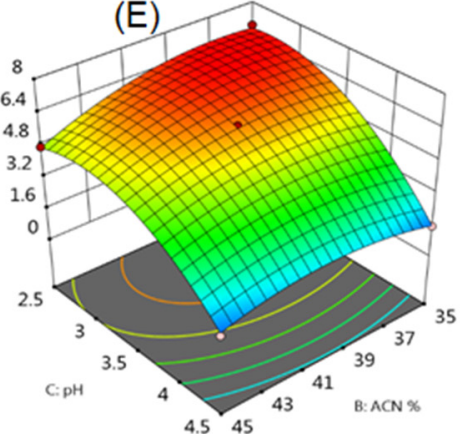

(C)

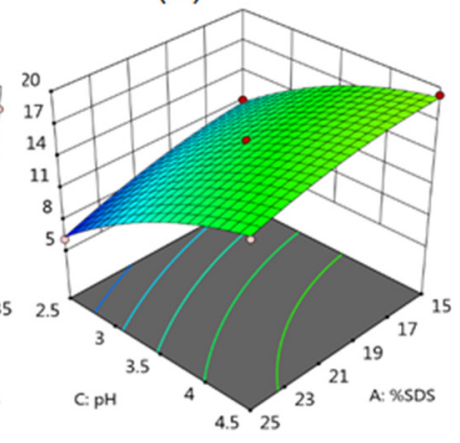

( $F)$

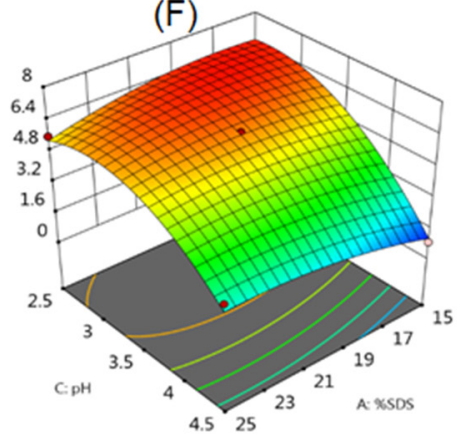

Figure 6. Response surface models showing the effect of percent of SDS, percent of acetonitrile and $\mathrm{pH}$ of the mobile phase on the resolution of MFH to RGE (A-C) and RGE to IS (D-F).

Multiple response process study indicated the effect of different parameters, further for final chromatographic condition, desirability function approach [53] was performed. In this, the conditions of the independent variable were assessed to get a targeted output of responses. RSM demonstrated that a decrease in the acetonitrile concentration and increase in the $\mathrm{pH}$ exhibited better resolution, however, the run time was more than $4 \mathrm{~min}$. Further, the low concentration of SDS eluted the MFH just after the dead volume; hence, there is a chance of interference with formulation excipients. Hence, to increase the retention time of MFH and to develop the rapid HPLC method the concentration of SDS was set to $20 \mathrm{mM}$ to $25 \mathrm{mM}$ and percent of acetonitrile was set to $40-45 \%$. Figure 7 showed the chromatographic condition for good resolution of the analytes and the desirability of independent 
variables and response. The desirability value $(0 \leq \mathrm{d} \geq 1)$ near to 1 indicates it is inside the acceptable range, hence, the quality of the response is acceptable. Software suggested 47 solutions; the optimum chromatographic conditions for developing rapid HPLC method with the good resolution were $25 \mathrm{mM}$ SDS, $42 \%$ acetonitrile concentration, and mobile phase pH 3.5 with a desirability of 1.
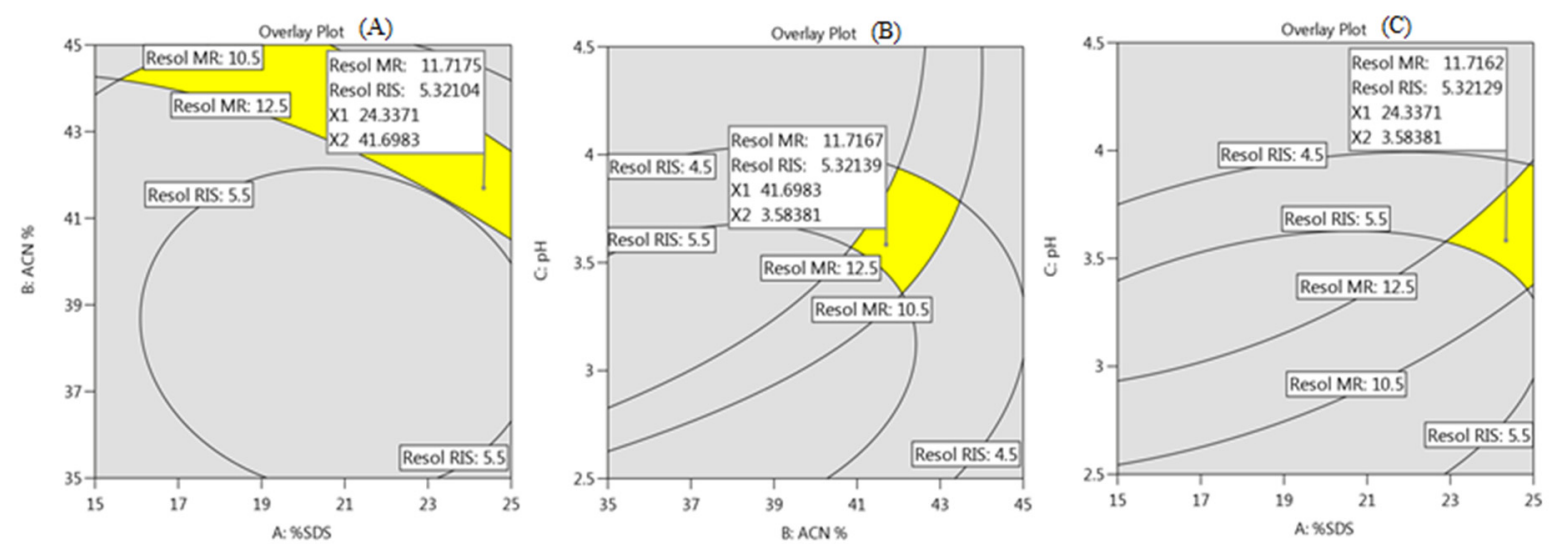

Figure 7. Overlay plot for optimum chromatographic conditions suggested by Design Expert software. $\%$ SDS against $\%$ of acetonitrile (A); \% of acetonitrile against mobile phase $\mathrm{pH}(\mathbf{B}) ; \%$ SDS against mobile phase $\mathrm{pH}(\mathbf{C})$.

To validate the suggested conditions, five experiments were conducted using the final mobile phase consisting of $10 \mathrm{mM}$ phosphate buffer with $25 \mathrm{mM}$ SDS, (pH 3.5) and acetonitrile in a ratio of 58:42 $v / v$, respectively. The resolution of MFH to RGE and RGE to IS was found to be 11.77 and 5.14, respectively, as compared to the predicted 11.71 and 5.32 by the model. The chromatogram showed good resolution, with good symmetric peak shape in the short run time. (Figure 8). An optimized chromatographic condition was used for running standard and sample solutions (Figure S1).
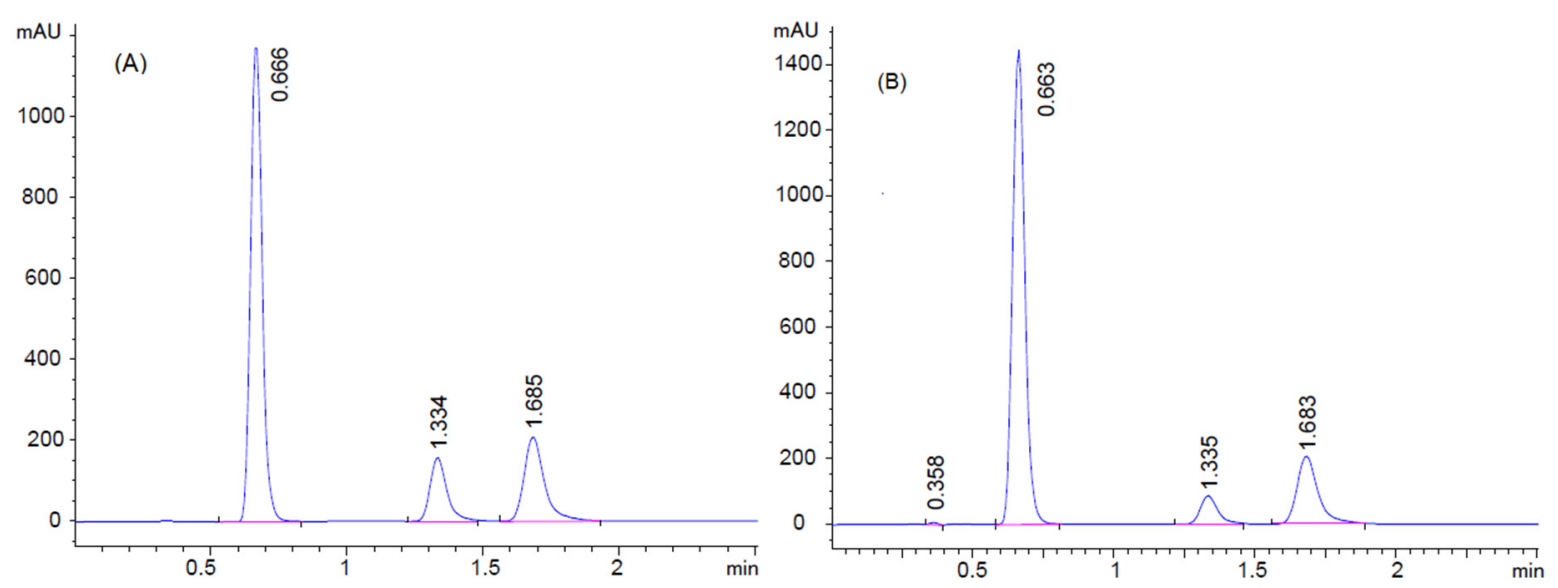

Figure 8. Representative chromatograms of standard solution (A) and formulation solution (B). The retention time of RFH:0.66 min, RGE:1.33 min, and IS:1.68 min.

\subsection{Validation}

\subsubsection{System Suitability Tests for the HPLC Method}

As per the standard guidelines, the determination of system suitability parameters is a part of chromatographic method developments. Retention time, resolution, theoretical plate, and tailing factor were calculated and tabulated in Table 2. The theoretical plate was found to be low because of the short monolithic column. 
Table 2. System suitability results for analytes by RP HPLC method.

\begin{tabular}{cccc}
\hline Parameters & MFH & RGE & IS \\
\hline Retention Time \pm SD & $0.66 \pm 0.019$ & $1.31 \pm 0.022$ & $1.69 \pm 0.012$ \\
Peak area \pm SD & $4294.15 \pm 41.48^{\mathrm{a}}$ & $363.12 \pm 6.95^{\mathrm{b}}$ & $1070.01 \pm 25.57^{\mathrm{c}}$ \\
Resolution \pm SD & - & $11.77 \pm 0.65^{\mathrm{d}}$ & $5.14 \pm 0.25^{\mathrm{e}}$ \\
Theoretical plate \pm SD & $748.54 \pm 15.83$ & $1003.62 \pm 25.71$ & $1151.91 \pm 47.28$ \\
Tailing factor \pm SD & $0.97 \pm 0.034$ & $0.89 \pm 0.013$ & $0.81 \pm 0.024$ \\
\hline
\end{tabular}

a $100 \mu \mathrm{g} / \mathrm{mL}^{\text {b }} 20 \mu \mathrm{g} / \mathrm{mL} ;{ }^{\mathrm{c}} 50 \mu \mathrm{g} / \mathrm{mL}$ solution: ${ }^{\mathrm{d}}$ between MFH and RGE; ${ }^{\mathrm{e}}$ between RGE and IS; SD: Standard Deviation of six replicates.

\subsubsection{Linearly}

A calibration curve (Figure S2) was constructed for both analytes by computing the absorption of second-derivative spectra at $243 \mathrm{~nm}$ for RGE (Figure 9A) and $235.5 \mathrm{~nm}$ for MFH (Figure 9B). The RGE exhibited good linearity in the concentration of 1 to $24 \mu \mathrm{g} / \mathrm{mL}$ and MFH in the concentration of 2 to $30 \mu \mathrm{g} / \mathrm{mL}$ with a good regression coefficient $(\mathrm{R} 2 \geq 0.999)$ Table 3 . The spectra were measured in triplicate for each concentration of both analytes.
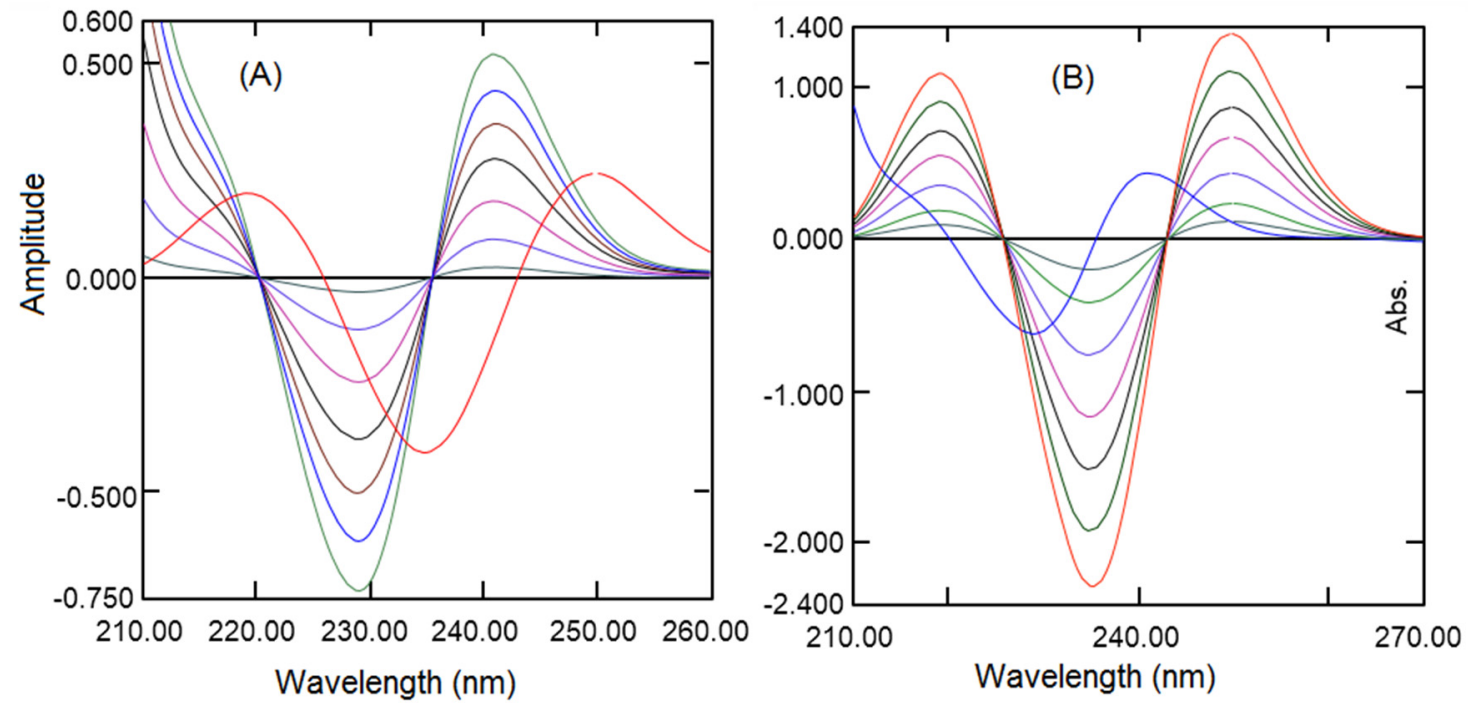

Figure 9. Second-derivative spectra of metformin $(2.0,5,10,15,20,25$, and $30 \mu \mathrm{g} / \mathrm{mL}$ ) with RGE (red) (A) and second derivative spectra of $\operatorname{RGE}(1,2,4,8,12,1620$ and $24 \mu \mathrm{g} / \mathrm{mL}$ ) with MFH (blue) (B).

Table 3. Calibration parameters results for both the proposed methods.

\begin{tabular}{lllll}
\hline & \multicolumn{2}{l}{ HPLC Method } & \multicolumn{2}{l}{ UV Spectroscopic Method } \\
\hline Parameters & MFH & RGE & MFH & RGE \\
\hline Linearity & & & & \\
Wavelength $(\mathrm{nm})$ & 230.0 & 230.0 & 235.5 & 243.0 \\
Linearity range $(\mu \mathrm{g} / \mathrm{mL})$ & $5-200$ & $2-150$ & $2-30$ & $1-24$ \\
Slope & 0.0353 & 0.0163 & 0.0753 & 0.0248 \\
Intercept & +0.355 & +0.019 & +0.015 & +0.0035 \\
Regression coefficient $(\mathrm{r} 2)$ & 0.9989 & 0.9993 & 0.9997 & 0.9991 \\
\hline Sensitivity & & & & \\
\hline LOD $(\mu \mathrm{g} / \mathrm{mL})$ & 1.49 & 0.48 & 0.54 & 0.24 \\
LOQ $(\mu \mathrm{g} / \mathrm{mL})$ & 4.53 & 1.56 & 1.68 & 0.76 \\
\hline
\end{tabular}

HPLC calibration curves (Figure S3) were developed by drawing a graph between the peak area ratios for both the analytes to IS against the respective concentration of RGE and MEH. The linear 
relationship for RGE and MEH was accomplished in the concentration range of $2-150 \mu \mathrm{g} / \mathrm{mL}$, and $5-200 \mu \mathrm{g} / \mathrm{mL}$ respectively (Table 3).

\subsubsection{Limit of Detection and Quantification}

The LOD and LOQ were calculated utilizing the standard deviation of the response and slopes of the three calibration curves. The results are presented in Table 3, low LOD and LOQ for both analytes revealed good sensitivity of both the proposed analytical procedures.

\subsubsection{Precision and Accuracy}

Inter day and intraday precision and accuracy of both the methods were determined by evaluating four different concentrations of both analytes on the same day and three following days respectively. (Figure S4) The \%RSD was found to be in the range of 0.61-1.78 for RGE and 0.68-1.91 For MFH (Table 4) indicating the good precision of the optimized spectroscopic and HPLC methods. The \%RE was found to be -1.75 to 1.81 for RGE and -1.96 to 1.20 for MFH, and exhibited good accuracy of the methods.

Table 4. Precision and accuracy results of MFH and RGE by the proposed methods.

\begin{tabular}{|c|c|c|c|c|c|c|c|}
\hline \multirow[b]{2}{*}{ Drug } & \multirow{2}{*}{$\begin{array}{l}\text { Amount of Drug } \\
{[\mu \mathrm{g} / \mathrm{mL}]}\end{array}$} & \multicolumn{3}{|c|}{ Inter Day } & \multicolumn{3}{|c|}{ Intra Day } \\
\hline & & $\begin{array}{l}\text { Amount Found } \\
\text { Mean }^{\mathrm{a}} \pm S D\end{array}$ & $\%$ RSD & $\% \mathrm{RE}$ & $\begin{array}{l}\text { Amount Found } \\
\text { Mean }^{b} \pm S D\end{array}$ & $\%$ RSD & $\%$ RE \\
\hline \multicolumn{8}{|c|}{ UV spectroscopic method } \\
\hline \multirow{4}{*}{ RGE } & 2 & $2.01 \pm 0.02$ & 1.00 & 0.50 & $1.99 \pm 0.03$ & 1.51 & -0.50 \\
\hline & 8 & $7.86 \pm 0.14$ & 1.78 & -1.75 & $7.93 \pm 0.11$ & 1.39 & -0.88 \\
\hline & 15 & $14.9 \pm 0.25$ & 1.68 & -0.67 & $15.07 \pm 0.25$ & 1.66 & 0.47 \\
\hline & 20 & $19.76 \pm 0.27$ & 1.37 & -1.20 & $19.8 \pm 0.12$ & 0.61 & -1.00 \\
\hline \multirow{4}{*}{ MFH } & 5 & $4.93 \pm 0.07$ & 1.42 & -1.40 & $5.06 \pm 0.09$ & 1.78 & 1.20 \\
\hline & 15 & $15.09 \pm 0.13$ & 0.86 & 0.60 & $14.79 \pm 0.17$ & 1.15 & -1.40 \\
\hline & 20 & $19.72 \pm 0.31$ & 1.57 & -1.40 & $19.75 \pm 0.16$ & 0.81 & -1.25 \\
\hline & 30 & $29.87 \pm 0.36$ & 1.21 & -0.43 & $29.68 \pm 0.34$ & 1.15 & -1.07 \\
\hline \multicolumn{8}{|c|}{ HPLC Method } \\
\hline \multirow{4}{*}{ RGE } & 5 & $5.01 \pm 0.07$ & 1.40 & 0.20 & $4.87 \pm 0.08$ & 1.64 & -2.60 \\
\hline & 50 & $49.69 \pm 0.43$ & 0.87 & -0.62 & $50.13 \pm 0.32$ & 0.64 & 0.26 \\
\hline & 100 & $101.81 \pm 1.45$ & 1.42 & 1.81 & $98.69 \pm 0.93$ & 0.94 & -1.31 \\
\hline & 150 & $148.89 \pm 2.08$ & 1.40 & -0.74 & $148.82 \pm 1.99$ & 1.34 & -0.79 \\
\hline \multirow{4}{*}{ MFH } & 25 & $24.67 \pm 0.39$ & 1.58 & -1.32 & $25.15 \pm 0.17$ & 0.68 & 0.60 \\
\hline & 50 & $49.11 \pm 0.94$ & 1.91 & -1.78 & $49.02 \pm 0.69$ & 1.41 & -1.96 \\
\hline & 100 & $99.03 \pm 1.34$ & 1.35 & -0.97 & $98.73 \pm 1.52$ & 1.54 & -1.27 \\
\hline & 200 & $201.59 \pm 1.83$ & 0.91 & 0.80 & $197.78 \pm 1.59$ & 0.80 & -1.11 \\
\hline
\end{tabular}

${ }^{a} \mathrm{n}=3 ;{ }^{\mathrm{b}} \mathrm{n}=9$; SD: Standard deviation; \%RSD: Percent relative standard deviation; \%RE: Percent relative error.

\subsubsection{Recovery Study}

A recovery study of both the analytical approaches was assessed by analyzing both analytes at three dissimilar concentration levels $(50 \%, 100 \%$, and $150 \%)$ and calculating the percentage recovery and \%RE. Results (Table 5) showed a mean percent recovery of $99.61 \%$ for RGE and $99.19 \%$ for MEH by the spectroscopic method and $99.57 \%$ for RGE and $98.96 \%$ for MEH by the HPLC method. The \%RE was also found to be below $\pm 2 \%$ for both analytes by both the methods demonstrating the high recovery of analytes by both the analytical approaches. 
Table 5. Recovery studies.

\begin{tabular}{|c|c|c|c|c|c|c|}
\hline \multirow[b]{2}{*}{ Drug } & \multicolumn{3}{|c|}{ UV Spectroscopic Method } & \multicolumn{3}{|c|}{ HPLC Method } \\
\hline & $\begin{array}{c}\text { Amount Added in } \\
{[\mu \mathrm{g} / \mathrm{mL}]}\end{array}$ & $\%$ Recovery & $\%$ RE & $\begin{array}{c}\text { Amount Added in } \\
{[\mu \mathrm{g} / \mathrm{mL}]}\end{array}$ & \%Recovery & $\%$ RE \\
\hline \multirow{5}{*}{ RGE } & 1 & 101.00 & 1.00 & 5 & 100.40 & 0.40 \\
\hline & 2 & 98.50 & -1.50 & 10 & 99.50 & -0.50 \\
\hline & 3 & 99.33 & -0.67 & 15 & 98.80 & -1.20 \\
\hline & Across Mean & 99.61 & & & 99.57 & \\
\hline & \%RSD & 1.27 & & & 0.80 & \\
\hline \multirow{5}{*}{$\mathrm{MFH}$} & 5 & 98.40 & -1.60 & 25 & 99.24 & -0.76 \\
\hline & 10 & 100.10 & 0.10 & 50 & 98.06 & -1.94 \\
\hline & 15 & 99.07 & -0.93 & 75 & 99.59 & -0.41 \\
\hline & Across Mean & 99.19 & & & 98.96 & \\
\hline & \%RSD & 0.85 & & & 0.81 & \\
\hline
\end{tabular}

\subsubsection{Robustness}

According to ICH, a robustness test should be performed to know the effect of slight changes in the experimental condition on the analysis results. The three important factors considered are the percentage of acetonitrile, mobile phase $\mathrm{pH}$, and flow rate. Further, the final concentration of the analytes was calculated by determining the peak area ratios of the analyte to the IS. Hence, the peak area ratio of MFH to IS and RGE to IS was selected as a response for studying the effect of changes in the experimental conditions. The experiments were conducted by altering three factors at three levels according to Box-Behnken experimental design (Table S1). The Pareto charts, generated using Design Expert software, displays the influence of the coincident discrepancy of variables on the peak area ratios. If the effects are beyond the Bonferroni Limit, those factors are highly significant, whereas the effects beyond the $t$-value limit are significant and effects less than the $t$-value limit are not significant. The Pareto diagram (Figure 10I,II) showed that a slight change in all three factors did not show any impact on the chromatogram peak area, indicating the robustness of the proposed HPLC method.
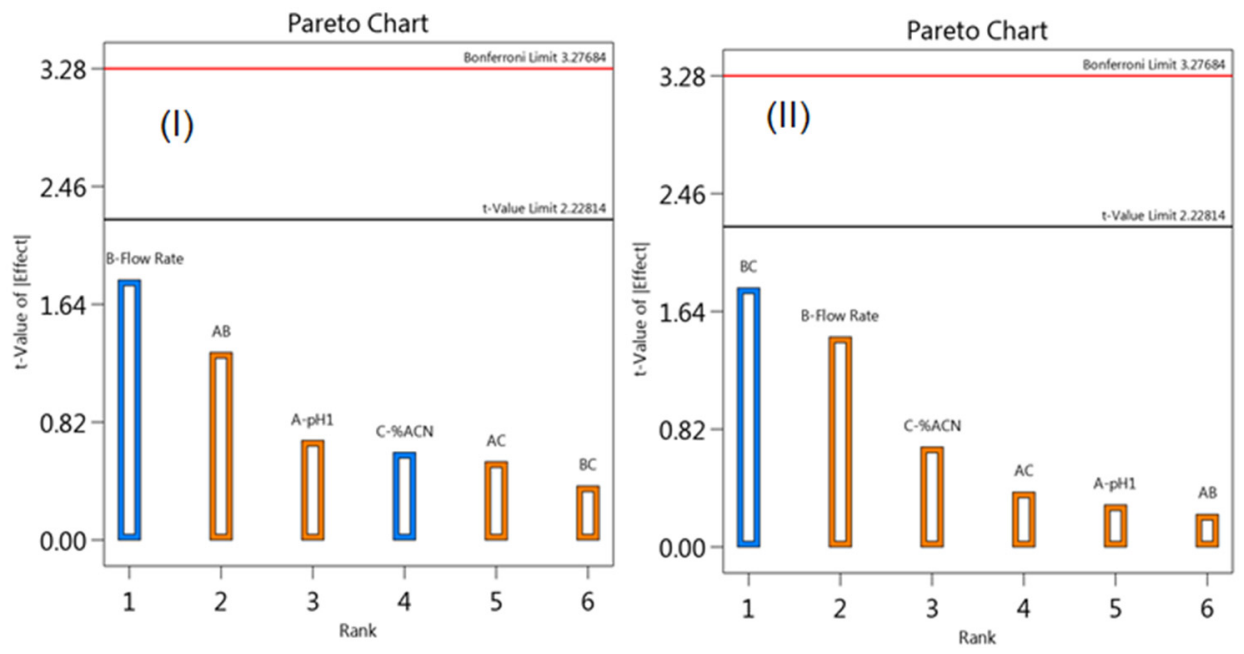

Figure 10. Pareto Chart showing the effects of percent of SDS (A), percent of acetonitrile (B) and $\mathrm{pH}$ of the mobile phase (C) on the resolution of MFH to RGE (I) and RGE to IS (II).

\subsection{Analysis of Laboratory Mixed Solutions and Formulations}

Second-derivative spectroscopic and optimized HPLC methods were applied for the concurrent quantification of MFH and RGE from laboratory prepared solutions (Figure S4) and formulation (Figure S4). The percent assay was found to be $98.29-101.35 \%$ for MFG and $98.13-101.39 \%$ for RGE 
from laboratory mixed solutions (Table 6). The amount of MFH and RGE determined from formulation agree with the actual amount (Table 7), indicating the absence of effect of formulation excipient on the analysis. Further, both the proposed procedures were statistically compared using the student-t-test and F-test. The experimental $t$ and $F$ values (Table 7) were less than the critical values, indicated that the results obtained by both the methods were non-significant.

Table 6. Analysis results of laboratory mixed solutions by the proposed methods.

\begin{tabular}{|c|c|c|c|c|c|}
\hline \multirow{2}{*}{$\begin{array}{c}\text { Ratios }^{a} \\
\text { RGE: MFH }\end{array}$} & \multicolumn{2}{|c|}{ UV Method (\%Recovory \pm SD) } & \multirow{2}{*}{ Ratiosa RGE: MFH } & \multicolumn{2}{|c|}{ HPLC Method (\%Recovory \pm SD) } \\
\hline & Remogliflozin & Metformin & & Remogliflozin & Metformin \\
\hline $2: 05$ & $101.23 \pm 0.01$ & $99.50 \pm 0.02$ & $5: 25$ & $100.90 \pm 0.07$ & $98.29 \pm 0.09$ \\
\hline $5: 30$ & $99.68 \pm 0.04$ & $98.58 \pm 0.03$ & $5: 100$ & $99.29 \pm 0.19$ & $99.04 \pm 0.17$ \\
\hline $10: 05$ & $100.98 \pm 0.15$ & $99.71 \pm 0.08$ & $75: 200$ & $101.06 \pm 0.21$ & $101.35 \pm 0.06$ \\
\hline $10: 20$ & $98.82 \pm 0.09$ & $101.32 \pm 0.12$ & $75: 100$ & $99.18 \pm 0.11$ & $99.77 \pm 0.15$ \\
\hline $20: 20$ & $99.16 \pm 0.32$ & $100.94 \pm 0.14$ & $150: 200$ & $101.35 \pm 0.24$ & $98.51 \pm 0.23$ \\
\hline $20: 30$ & $101.39 \pm 0.21$ & $99.30 \pm 0.18$ & $150: 25$ & $98.13 \pm 0.35$ & $98.39 \pm 0.31$ \\
\hline
\end{tabular}

Table 7. Assay of formulation and statistical calculation results.

\begin{tabular}{|c|c|c|c|c|}
\hline & \multicolumn{2}{|c|}{ UV Spectroscopic Method } & \multicolumn{2}{|c|}{ HPLC Method } \\
\hline & RGE & MFH & RGE & MFH \\
\hline Label Claim (mg) & 100 & 500 & 100 & 500 \\
\hline Amount taken $[\mu \mathrm{g} / \mathrm{mL}]$ & 4 & 20 & 20 & 100 \\
\hline Amount found $[\mu \mathrm{g} / \mathrm{mL}]$ & 3.95 & 20.04 & 19.83 & 98.48 \\
\hline Label Claim (mg) & 100 & 1000 & 100 & 1000 \\
\hline Amount taken $[\mu \mathrm{g} / \mathrm{mL}]$ & 3 & 30 & 15 & 150 \\
\hline Amount found $[\mu \mathrm{g} / \mathrm{mL}]$ & 2.97 & 29.78 & 15.12 & 148.24 \\
\hline Mean \%estimation ${ }^{a}$ & 99.51 & 99.60 & 99.80 & 100.07 \\
\hline \%RSD & 1.34 & 0.89 & 0.78 & 1.08 \\
\hline $\mathrm{n}$ & 6 & 6 & & \\
\hline Student $t$-test $(2.306)^{\mathrm{b}}$ & 0.711 & 0.450 & & \\
\hline$F(6.388)^{c}$ & 3.521 & 1.436 & & \\
\hline
\end{tabular}

a Mean of three determination at each level; ${ }^{\mathrm{b}}$ critical value of $\mathrm{t}$ at $p=0.05{ }^{\mathrm{c}}$ critical value of $\mathrm{F}$ at $p=0.05$.

\section{Conclusions}

Two simple analytical procedures were established for the concurrent determination of RGE and MFH from laboratory mixed solutions and tablets without prior separation. The UV spectroscopic method was economical and eco-friendly as water has been used as a solvent. The second-order derivative technique was used which eliminated the absorption effect of another analyte as well as excipients. HPLC method was optimized using the design of the experiment and data were generated employing Design-Expert software. The independent variables percent of SDS, percent of acetonitrile, and mobile phase $\mathrm{pH}$ exhibited a substantial influence on the resolution of analytes, which was confirmed by ANOVA. The actual $R^{2}$ and adjusted $R^{2}$ values were close and adequacy precision ratio was high indicating the good fit of the model and can navigate through the design space. The analysis results were also presented as diagnostic plots, perturbation plots, and response surface models. The optimized chromatographic technique was simple, rapid, precise, and robust for the concurrent quantification of RGE and MFH from solid dosage forms. 
Supplementary Materials: The following are available online at http://www.mdpi.com/2297-8739/7/4/59/s1, Figure S1. Chromatograms of standard solutions of metformin and remogliflozin (MFH:RGE $(\mu \mathrm{g} / \mathrm{mL})=25: 5(\mathrm{~A})$; 50:25 (B), 75:50 (C); 100:75 (D); 125:100 (E); 150:125 (F); to 200:150 (G) and samples 100:10 (H) and 200:20 (I). Figure S2. Calibration curves for RGE and MFH by second-derivative UV spectroscopic method. Figure S3: Calibration curves for RGE and MFH by RP-HPLC method. Figure S4. Normal and second-derivative UV spectra of MFH and RGE for accuracy and precision, laboratory mixed solutions, and formulations. Table S1. Results of the Box-Behnken model for robustness study.

Author Contributions: Conceptualization: M.A. and K.N.V.; data curation: R.E.E.E., R.S., M.M.I., K.N.V., and A.A.B.; formal analysis: M.A., R.E.E.E., M.M.I., K.N.V., S.N., and A.A.B.; funding acquisition: M.A., K.N.V., and S.N.; investigation: R.E.E.E., R.S., K.N.V., S.N., and A.A.B.; methodology: M.A., R.E.E.E., R.S., and A.A.B.; project administration: S.N.; resources: R.E.E.E., R.S., and M.M.I.; software: R.S.; supervision: M.M.I. and K.N.V.; validation: M.A., M.M.I., S.N., and A.A.B.; visualization: R.E.E.E., S.N., and A.A.B.; writing-original draft: M.A., R.E.E.E., R.S., M.M.I., S.N., and A.A.B.; writing-review and editing: M.A., M.M.I., and K.N.V. All authors have read and agreed to the published version of the manuscript.

Funding: The authors extend their appreciation to the Deputyship for Research and Innovation, Ministry of Education in Saudi Arabia for funding this research work through project number IFT20122.

Acknowledgments: The authors are grateful to the Deanship of Scientific Research, King Faisal University, Kingdom of Saudi Arabia for support and encouragement.

Conflicts of Interest: The authors have no conflict of interest.

\section{References}

1. Sami, W.; Ansari, T.; Butt, N.S.; Hamid, M.R.A. Effect of diet on type 2 diabetes mellitus: A review. Int. J. Health Sci. 2017, 11, 65-71. [CrossRef]

2. Magliano, D.J.; Sacre, J.W.; Harding, J.L.; Gregg, E.W.; Zimmet, P.Z.; Shaw, J.E. Young-onset type 2 diabetes mellitus-Implications for morbidity and mortality. Nat. Rev. Endocrinol. 2020, 16, 21-31. [CrossRef]

3. Layla, A.; Anjali, B.; Azeem, M. Prevalence's of overweight, obesity, hyperglycaemia, hypertension and dyslipidaemia in the Gulf: Systematic review. JRSM Short Rep. 2011, 2, 55. [CrossRef]

4. Moon, M.K.; Hur, K.Y.; Ko, S.H.; Park, S.O.; Lee, B.W.; Kim, J.H.; Rhee, S.Y.; Kim, H.; Choi, K.M.; Kim, N.H. Committee of Clinical Practice Guidelines of the Korean Diabetes Association. Combination therapy of oral hypoglycemic agents in patients with type 2 diabetes mellitus. Korean J. Intern. Med. 2017, 32, 974-983. [CrossRef] [PubMed]

5. Lin, Y.; Sun, Z. Current views on type 2 diabetes. J. Endocrinol. 2010, 204, 1-11. [CrossRef] [PubMed]

6. Rena, G.; Hardie, D.G.; Pearson, E.R. The mechanisms of action of metformin. Diabetologia 2017, 60, 1577-1585. [CrossRef]

7. Jabbour, S.; Ziring, B. Advantages of extended-release metformin in patients with type 2 diabetes mellitus. Postgrad Med. 2011, 123, 15-23. [CrossRef]

8. Setter, S.; Iltz, J.; Thams, J.; Campbell, R. Metformin Hydrochloride in the Treatment of Type 2 Diabetes Mellitus: A Clinical Review with a Focus on Dual Therapy. Clin. Ther. 2004, 25, 2991-3026. [CrossRef]

9. Mohan, V.; Mithal, A.; Joshi, S.R.; Aravind, S.R.; Chowdhury, S. Remogliflozin Etabonate in the Treatment of Type 2 Diabetes: Design, Development, and Place in Therapy. Drug Des. Dev. Ther. 2020, 14, 2487-2501. [CrossRef]

10. Markham, A. Remogliflozin Etabonate: First global approval. Drugs 2019, 79, 1157-1161. [CrossRef]

11. Simes, B.C.; MacGregor, G.G. Sodium-Glucose Cotransporter-2 (SGLT2) Inhibitors: A Clinician's Guide. Diabetes Metab. Syndr. Obes. 2019, 12, 2125-2136. [CrossRef] [PubMed]

12. Scheen, A.J. Pharmacodynamics, efficacy and safety of sodium-glucose co-transporter type 2 (SGLT2) inhibitors for the treatment of type 2 diabetes mellitus. Drugs 2015, 75, 33-59. [CrossRef] [PubMed]

13. Fujimori, Y.; Katsuno, K.; Nakashima, I.; Ishikawa-Takemura, Y.; Fujikura, H.; Isaji, M. Remogliflozin etabonate, in a novel category of selective low-affinity sodium glucose cotransporter (SGLT2) inhibitors, exhibits antidiabetic efficacy in rodent models. J. Pharmacol. Exp. Ther. 2008, 327, 268-276. [CrossRef] [PubMed]

14. Dharmalingam, M.; Aravind, S.R.; Thacker, H.; Paramesh, S.; Mohan, B.; Chawla, M.; Asirvatham, A.; Goyal, R.; Shembalkar, J.; Balamurugan, R.; et al. Efficacy and safety of Remogliflozin Etabonate, a new sodium glucose co-transporter-2 inhibitor, in patients with type 2 diabetes mellitus: A 24-week, randomized, double-blind, active-controlled trial. Drugs 2020, 11, 1-4. [CrossRef] 
15. Zelniker, T.A.; Wiviott, S.D.; Raz, I.; Im, K.; Goodrich, E.; Bonaca, M.P. SGLT2 inhibitors for primary and secondary prevention of cardiovascular and renal outcomes in type 2 diabetes: A systematic review and meta-analysis of cardiovascular outcome trials. Lancet 2019, 393, 31-39. [CrossRef]

16. Hussey, E.K.; Kapur, A.; O'Connor-Semmes, R.; Tao, W.; Rafferty, B.; Polli, J.W.; James, C.D.; Dobbins, R.L. Safety, pharmacokinetics and pharmacodynamics of remogliflozin etabonate, a novel SGLT2 inhibitor, and metformin when co-administered in subjects with type 2 diabetes mellitus. BMC Pharmacol. Toxicol. 2013, 14, 25. [CrossRef]

17. Al-Janabi, W.S.K.; Mahmood, A.K.; Luaibi, H.M. Determination of the Dissociation Constants of Metformin from a Second Derivative UV Spectrum. Int. J. Res. Pharm. Sci. 2020, 11, 790-796. [CrossRef]

18. Chhetri, H.P.; Thapa, P.; Schepdael, A.V. Simple HPLC-UV method for the quantification of metformin in human plasma with one step protein precipitation. Saudi Pharmaceut. J. 2014, 22, 483-487. [CrossRef]

19. Chaudhari, K.; Wang, J.; Xu, Y.; Winters, A.; Wang, L.; Dong, X.; Cheng, E.Y.; Liu, R.; Yang, S.H. Determination of metformin bio-distribution by LC-MS/MS in mice treated with a clinically relevant paradigm. PLoS ONE 2020, 15, e0234571. [CrossRef]

20. Ali, I.; Aboul-Enein, H.Y.; Gupta, V.K. Analysis of metformin dosage formulations by capillary electrophoresis at nano scale detection. Comb. Chem. High Throughput Screen. 2007, 10, 611-615. [CrossRef]

21. Majithia, R.H.; Khodadiya, A.; Patel, V.B. Spectrophotometric method development and validation for simultaneous estimation of Anagliptin and Metformin HCl BY Q-Absorption ratio method in synthetic mixture. Heliyon 2020, 6, e03855. [CrossRef]

22. Attimarad, M.V.; Nair, A.B.; Aldhubaib, B.E. Development of liquid chromatographic method for the simultaneous determination of metformin and miglitol in human plasma: Application to pharmacokinetic studies. J. Iranian Chem. Soc. 2015, 12, 1629-1636. [CrossRef]

23. Neelima, K.; Prasad, Y.R. Analytical method development and validation of metformin, voglibose, glimepiride in bulk and combined tablet dosage form by gradient RP-HPLC. Pharmaceut. Meth. 2014, 5, 27-33. [CrossRef]

24. Gedawy, A.; Al-Salami, H.; Dass, C.R. Development and validation of a new analytical HPLC method for simultaneous determination of the antidiabetic drugs, metformin and gliclazide. J. Food Drug Anal. 2019, 27, 315-322. [CrossRef] [PubMed]

25. Sebaiy, M.M.; El-Adl, S.M.; Baraka, M.M.; Hassan, A.A. Rapid RP-HPLC method for simultaneous estimation of metformin, pioglitazone, and glimepiride in human plasma. Acta Chromatogr. 2020, 32, 16-21. [CrossRef]

26. Shirode, A.; Maduskar, P.; Deodhar, M.; Kadam, V. RP-HPLC and HPTLC methods for simultaneous estimation of metformin hydrochloride and vildagliptin from bulk and marketed formulation: Development and validation. Br. J. Pharmaceut. Res. 2014, 4, 2370-2386. [CrossRef]

27. Antonopoulos, N.; Machairas, G.; Migias, G.; Vonaparti, A.; Brakoulia, V.; Pistos, C.; Gennimata, D.; Panderi, I. Hydrophilic Interaction Liquid Chromatography-Electrospray Ionization Mass Spectrometry for Therapeutic Drug Monitoring of Metformin and Rosuvastatin in Human Plasma. Molecules 2018, 23, 1548. [CrossRef]

28. Al Bratty, M.; Alhazmi, H.A.; Javed, S.A.; Lalitha, K.G.; Asmari, M.; Wölker, J.; El Deeb, S. Development and Validation of LC-MS/MS Method for Simultaneous Determination of Metformin and Four Gliptins in Human Plasma. Chromatographia 2017, 80, 891-899. [CrossRef]

29. Attimarad, M. Multivariate optimization of a capillary zone electrophoresis assay method for simultaneous quantification of metformin and vildagliptin from a formulation. J. Liq. Chrom. Relat. Technol. 2016, 39, 401-407. [CrossRef]

30. Alnajjar, A.O.; Idris, A.M.; Attimarad, M.V.; Elgorashe, R.E.E. Quadruple Response Factorial Design Optimization of Capillary Zone Electrophoresis Assay Procedure for Metformin and Sitagliptin Combination. J. Liq. Chrom. Relat. Technol. 2015, 38, 1379-1383. [CrossRef]

31. Mohamed, D.; Elshahed, M.S.; Nasr, T.; Aboutaleb, N.; Zakaria, O. Novel LC-MS/MS method for analysis of metformin and canagliflozin in human plasma: Application to a pharmacokinetic study. BMC Chem. 2019, 13, 82. [CrossRef] [PubMed]

32. Munde, M.K.; Kulkarni, N.S.; Khiste, R.H.; Sen, D.B. Development and Validation of Novel Analytical Method for Empagliflozin and Metformin Hydrochloride in Bulk and Pharmaceutical Dosage Form by Four Different Simultaneous Estimation Approaches using UV Spectroscopy. Res. J. Pharm. Technol. 2020, 13, 1236-1242. [CrossRef] 
33. Tayade, A.B.; Patil, A.S.; Shirkhedkar, A.A. Development and Validation of Zero Order UV-Spectrophotometric Method by Area under Curve Technique and High Performance Thin Layer Chromatography for the Estimation of Remogliflozin Etabonate in Bulk and In-House Tablets. Invent. Rapid Pharm. Anal. Qual. Assur. 2019, 3, 1-5.

34. Sigafoos, J.F.; Bowers, G.D.; Castellino, S.; Culp, A.G.; Wagner, D.S.; Reese, M.J.; Humphreys, J.E.; Hussey, E.K.; Semmes, R.L.C.; Kapur, A.; et al. Assessment of the drug interaction risk for remogliflozin etabonate, a sodium-dependent glucose cotransporter-2 inhibitor: Evidence from in vitro, human mass balance, and ketoconazole interaction studies. Drug Metab. Dispos. 2012, 40, 2090-2101. [CrossRef]

35. Tammisetty, M.; Challa, B.R.; Puttagunta, S.B. A novel analytical method for the simultaneous estimation of remogliflozin and metformin hydrochloride by UPLC/PDA in bulk and formulation. Application to the estimation of product traces. Turk. J. Pharm. Sci. 2020, 39699. [CrossRef]

36. Kamal, A.H.; El-Malla, S.F.; Hammad, S.F. A Review on UV spectrophotometric methods for simultaneous multicomponent analysis. Eur. J. Pharm. Med. Res. 2016, 3, 348-360.

37. Salinas, F.; Nevado, J.J.B.; Mansilla, A.E. A new spectrophotometric method for quantitative multicomponent analysis resolution of mixtures of salicylic and salicyluric acids. Talanta 1990, 37, 347-351. [CrossRef]

38. Chohan, M.S.; Elgorashe, R.E.E.; Balgoname, A.A.; Attimarad, M.; SreeHarsha, N.; Venugopala, K.N.; Nair, A.B.; Pottathil, S. Eco-friendly Derivative UV Spectrophotometric Methods for Simultaneous Determination of Diclofenac Sodium and Moxifloxacin in Laboratory Mixed Ophthalmic Preparation. Indian J. Pharm. Edu. Res. 2019, 53, 166-174. [CrossRef]

39. Bhatt, N.M.; Chavada, V.D.; Sanyal, M.; Shrivastav, P.S. Manipulating ratio spectra for the spectrophotometric analysis of diclofenac sodium and pantoprazole sodium in laboratory mixtures and tablet formulation. Sci. World J. 2014, 495739. [CrossRef]

40. Attimarad, M.; Chohan, M.S.; Balgoname, A.A. Simultaneous Determination of Moxifloxacin and Flavoxate by RP-HPLC and Ecofriendly Derivative Spectrophotometry Methods in Formulations. Int. J. Environ. Res. Public Health 2019, 16, 1196. [CrossRef]

41. Ganorkar, S.B.; Shirkhedkar, A.A. Design of experiments in liquid chromatography (HPLC) analysis of pharmaceuticals: Analytics, applications, implications and future prospects. Rev. Anal. Chem. 2017, 36, 20160025. [CrossRef]

42. Hashem, H.; El-Sayed, H.M. Quality by design approach for development and validation of a RP-HPLC method for simultaneous determination of co-administered levetiracetam and pyridoxine $\mathrm{HCl}$ in prepared tablets. Microchem. J. 2018, 143, 55-63. [CrossRef]

43. Hashem, H.; El-Sayed, H.M. Quality by Design Strategy for Simultaneous HPLC Determination of Bromhexine $\mathrm{HCl}$ and Its Metabolite Ambroxol $\mathrm{HCl}$ in Dosage Forms and Plasma. Chromatographia 2020, 83, 123-129. [CrossRef]

44. Peraman, R.; Bhadraya, K.; Reddy, Y.P.; Reddy, C.S.; Lokesh, T. Analytical Quality by Design Approach in RP-HPLC Method Development for the Assay of Etofenamate in Dosage Forms. Indian J. Pharm. Sci. 2015, 77, 751-757. [CrossRef]

45. Tome, T.; Žigart, N.; Časar, Z.; Obreza, A. Development and Optimization of Liquid Chromatography Analytical Methods by Using AQbD Principles: Overview and Recent Advances. Org. Process Res. Dev. 2019, 23, 1784-1802. [CrossRef]

46. Shao, J.; Cao, W.; Qu, H.; Pan, J.; Gong, X. A novel quality by design approach for developing an HPLC method to analyze herbal extracts: A case study of sugar content analysis. PLoS ONE 2018, 13, e0198515. [CrossRef]

47. Patel, K.G.; Shah, P.M.; Shah, P.A.; Gandhi, T.R. Validated high-performance thinlayer chromatographic (HPTLC) method for simultaneous determination of nadifloxacin, mometasone furoate, and miconazole nitrate cream using fractional factorial design. J. Food Drug Anal. 2016, 24, 610-619. [CrossRef]

48. Patel, K.G.; Patel, A.T.; Shah, P.A.; Gandhi, T.R. Multivariate optimization for simultaneous determination of aspirin and simvastatin by reverse phase liquid chromatographic method using AQbD approach. Bull. Fac. Pharm. Cairo Univ. 2017, 55, 293-301. [CrossRef]

49. Peng, X.; Yang, G.; Shi, Y.; Zhou, Y.; Zhang, M.; Li, S. Box-Behnken design based statistical modeling for the extraction and physicochemical properties of pectin from sunflower heads and the comparison with commercial low-methoxyl pectin. Sci. Rep. 2020, 10, 3595. [CrossRef] 
50. Tayeb, A.M.; Tony, M.A.; Mansour, S.A. Application of Box-Behnken factorial design for parameters optimization of basic dye removal using nano-hematite photo-Fenton tool. Appl. Water Sci. 2018, 8, 138. [CrossRef]

51. ICH Harmonized Tripartite Guideline; Text on Validation of Analytical Procedures, Text and Methodology, Q2 (R1), International Conference on Harmonization; ICH Secretariat, c/o IFPMA, 30 rue de St-Jean: Geneva, Switzerland, 2005; pp. 1-17.

52. Attimarad, M.; Sreeharsha, N.; Aldhubaib, B.E.; Nair, A.B.; Venugopala, K.N. Simultaneous determination of metformin and three gliptins in pharmaceutical formulations using RPHPLC: Application to stability studies on linagliptin tablet formulation. Indian J. Pharm. Edu. Res. 2014, 48, 45-53. [CrossRef]

53. Lee, D.H.; Jeong, I.J. A desirability function method for optimizing mean and variability of multiple responses using a posterior preference articulation approach. Qual. Reliab. Eng. Int. 2018, 34, 360-376. [CrossRef]

Publisher's Note: MDPI stays neutral with regard to jurisdictional claims in published maps and institutional affiliations.

(C) 2020 by the authors. Licensee MDPI, Basel, Switzerland. This article is an open access article distributed under the terms and conditions of the Creative Commons Attribution (CC BY) license (http://creativecommons.org/licenses/by/4.0/). 